\title{
RENAL PATHOLOGY IN END-STAGE RENAL DISEASE ASSOCIATED WITH PARAPLEGIA
}

By C. H. Barton, M.D., N. D. Vaziri, M.D., S. Gordon, M.D. and S. Tilles, M.D.

${ }^{1}$ Division of Nephrology, University of California, ${ }^{2}$ Irvine Medical Center, Irvine, California and ${ }^{3}$ SCI Service, Long Beach VA Medical Center, Long Beach, California, U.S.A.

Summary. In the present study we report the renal pathological findings from autopsy material along with relevant clinical data on 2 I spinal cord injury patients with end-stage renal disease (SCI-ESRD) treated with maintenance haemodialysis. These data are compared with the relevant clinical and post-mortem findings on 43 ambulatory dialysis patients who expired during the same time period.

The SCI-ESRD patients exhibited markedly different clinical and renal histopathological data when compared to the ambulatory-ESRD group. Chronic pyelonephritis and amyloidosis dominated the findings and were the major causes of renal insufficiency. Acute pyelonephritis, papillary necrosis, calculous disease, pyonephrosis and perinephric abscess formation were also more frequently present in the SCI-ESRD patients. Hypertension and nephrosclerosis, which were common findings in the ambulatory-ESRD patients were comparatively rare in the SCIESRD patients. In addition, the incidence of acquired cystic disease (ACD) was considerably less in the SCI-ESRD group. Although the reasons for these findings are not entirely clear several possible explanations are given.

Infection with gram negative sepsis was the predominant cause of death in the SCI-ESRD patients, while death secondary to cardiovascular disease predominated in the ambulatory-ESRD group. Furthermore, the urinary tract and infected decubitus ulcers were determined to be the major source for sepsis in the SCI patients. From these findings it would follow that more effective prevention and control of these infections would result in not only a lower incidence of renal failure but also a substantially reduced morbidity and mortality in chronic SCI.

Key words: Spinal cord injury; Spinal paralysis; Renal pathology; End-stage renal disease; Haemodialysis.

\section{Introduction}

END-STAGE RENAL DISEASE (ESRD), a well known complication of longstanding spinal cord injury (SCI) is generally the result of some combination of urinary tract infection, calculous disease, obstruction and/or secondary amyloidosis (Pearce et al., I964; Tribe et al., I969). Prior to the availability of supportive dialysis, renal failure was estimated to be the cause of death in up to 75 per cent of these patients. (Burr, I972). In the past decade, since the routine application of haemodialysis and use of other modern

\footnotetext{
* This study was generously funded by the late Eldore G. Reines. This paper was in part presented before the Annual Meeting of the American Society of Paraplegia, September, I 982 in Las Vegas, Nevada.

$\star \star$ Reprint requests: Cyril H. Barton, M.D., Nephrology Division, University of California Medical Center, IOI City Drive So., Orange, Calif. 92668.
} 
therapeutic modalities in the support and treatment of SCI, little imformation has been reported regarding patient survival, cause of death and aetiology of renal insufficiency in these patients. Recently, however, our group reported survival data on 40 SCI patients treated with maintenance haemodialysis (Mirahmadi et al., I982). In the present study we report the renal pathological findings from autopsy material on 2 I SCI-ESRD patients treated with maintenance haemodialysis, who expired at our institution between February, I973 and July, I979. These data are compared with the autopsy findings on 43 ambulatory dialysis patients who expired during the same time period. Relevant clinical data were also reviewed in both groups and correlated with the pathological findings regarding aetiology of renal failure and cause of death.

\section{Patients and Methods}

Relevant clinical and postmortem data were reviewed in 2 I spinal cord injury patients with ESRD (SCI-ESRD) and 43 ambulatory patients with ESRD (ambulatory-ESRD) who had expired at our institution between February, I973 and July, I979. The SCI-ESRD group consisted of 2 I male patients, aged $46 \pm 10.3$ years. The level of spinal cord injury was $\mathrm{C}_{4}$ to $\mathrm{C}_{6}$ in 33 per cent $\mathrm{T}_{\mathrm{I}}$ to $\mathrm{T}_{5}$ in 33 per cent and $\mathrm{T}_{6}$ to $\mathrm{T}_{\mathrm{I}} 2$ in 33 per cent of the patients. Duration of spinal cord injury was $20.7 \pm 8.5$ years, range 6 to 32 years. Maintenance haemodialysis had been performed for a duration of $17 \pm 16$ months, range $I$ to 60 months. The ambulatory ESRD group consisted of 43 male patients, aged $54 \pm$ Io years and maintenance haemodialysis had been performed for $43 \pm 17$ months, range I to 70 months. Both groups received similar incentre dialysis treatments at the same institution for periods of 4-6 hours 2-3 times a week. Hollow fibre or parallel flow dialyzers were utilized with a proportioning dialysate delivery system and single pass dialysate flow rates of $500 \mathrm{ml} / \mathrm{min}$. A conventional glucose-free dialysate was used containing $\mathrm{Na}^{+}, 135 \mathrm{mEq} / \mathrm{L}$; $\mathrm{Cl}^{-}$I00 mEq/L; Acetate $35 \mathrm{mEq} / \mathrm{L} ; \mathrm{Ca}^{++}, 3-3.5 \mathrm{mEq} / \mathrm{L} ; \mathrm{Mg}^{++}, \mathrm{I} \cdot 2$ $\mathrm{mEq} / \mathrm{L}$, and $\mathrm{K}^{+}, 0.0-3.0 \mathrm{mEq} / \mathrm{L}$. In both groups, dietary restrictions were limited to sodium and potassium as needed with no protein or caloric restrictions imposed. All patients received folic acid ( $\mathrm{I} \mathrm{mg} / \mathrm{day}$ ) and multivitamins. Aluminum carbonate and oral or parenteral iron compounds were administered as needed to treat hyperphosphatemia and anaemia, respectively. Similar drug regimens were also used in both groups to control hypertension.

In both groups, the kidneys had been examined grossly and microscopically by staff pathologists and morphological descriptions and diagnoses were obtained retrospectively from the pathology reports. In addition, extensive clinical data were reviewed on each patient and correlated with the pathological material to facilitate a better understanding of the underlying renal diseases, associated medical and surgical problems and direct cause of death. As it is generally agreed that the bacterial nature of chronic interstitial renal disease can't be inferred solely on the basis of morphologic examination of the kidneys, we also utilized available clinical data in making a diagnosis of chronic pyelonephritis. For the purposes of this study, a diagnosis of chronic pyelonephritis was made only in those cases with both clinical and pathological evidence for this disease. A patient 
was considered to have clinical evidence for chronic pyelonephritis if this diagnosis appeared in the medical chart or if the patient had three or more episodes of acute pyelonephritis and functional evidence of renal disease. Histopathological evidence for chronic pyelonephritis was defined by the characteristic chronic interstitial inflammatory changes, fibrosis, tubular atrophy, dilatation and colloid cast formation. When chronic interstitial changes were present in the kidney without accompanying clinical evidence for chronic pyelonephritis, a diagnosis of chronic interstitial nephritis of unknown aetiology was made. Available clinical data were also used to support the morphological diagnosis of nonspecific chronic glomerulonephritis, lupus nephritis, diabetic intercapillary glomerulosclerosis, scleroderma kidney, polyarteritis nodosa and polycystic kidney disease (PCKD).

\section{Results}

\section{SCI-ESRD Patients}

Renal pathological findings and major causes of renal failure are shown in Table I. In this group, 37 kidneys were examined from 21 subjects. In five patients prior unilateral nephrectomy had been performed for problems related to chronic infection and nephrolithiasis. The most common pathological abnormality noted was chronic pyelonephritis, present in 2 I of the $2 \mathrm{I}$ cases. Indwelling Foley catheters, suprapubic cystostomy or nephrostomy tubes had been placed in most patients to maintain urine flow and all patients had a positive history for persistent or recurrent urinary tract infection and pyelonephritis. In six of the 2 I cases, superimposed acute pyelonephritis was also present. Renal abscesses were present in 5 out of $2 \mathrm{I}$; four of these were perinephric, one was an intrarenal medullary abscess. In 16 of the 21 cases, extensive amyloid deposition was found

\section{TABLE I}

Renal pathological findings and causes of renal failure in 2 I SCI-ESRD patients

\begin{tabular}{|c|c|c|c|c|c|c|}
\hline Pathological findings & $\begin{array}{c}\text { No. of } \\
\text { cases } \\
\text { present }\end{array}$ & $\begin{array}{c}\% \\
\text { Total }\end{array}$ & $\begin{array}{l}\text { Major } \\
\text { cause of } \\
\text { of renal } \\
\text { failure }\end{array}$ & Total & $\begin{array}{l}\text { May } \\
\text { have } \\
\text { contri- } \\
\text { buted to } \\
\text { renal } \\
\text { failure }\end{array}$ & $\begin{array}{c}\% \\
\text { Total }\end{array}$ \\
\hline Chronic Pyelonephritis & 2 I & I 00 & $2 \mathrm{I}$ & IOO & - & - \\
\hline Acute Pyelonephritis & 6 & $28 \cdot 6$ & - & - & ? & - \\
\hline Amyloidosis & I 7 & $8 \mathrm{I}$ & I7 & $8 \mathrm{I}$ & - & - \\
\hline Calculous Disease & I 2 & 57 & - & - & 12 & $57 \cdot 1$ \\
\hline Obstructive uropathy & I 2 & 57 & I I & $52 \cdot 4$ & I & $4 \cdot 8$ \\
\hline Renal and/or perinephric abscess & 5 & $23 \cdot 8$ & - & - & ? & - \\
\hline Nephrosclerosis & 6 & 28.6 & - & - & 6 & $28 \cdot 6$ \\
\hline Renal Carcinoma & I & $4 \cdot 8$ & - & - & - & - \\
\hline Renal Adenoma & 4 & 19 & - & - & - & - \\
\hline Papillary Necrosis & 3 & $14 \cdot 3$ & — & - & 3 & $14 \cdot 3$ \\
\hline PCKD & I & $4 \cdot 8$ & I & $4 \cdot 8$ & - & - \\
\hline
\end{tabular}


involving glomeruli, blood vessels and/or tubules. Multiple renal calculi were present in Io of 2 I subjects, involving the calyces, pelvis and proximal ureters. They were bilateral in seven cases and unilateral in three. However, in two of the three cases, calculi involved the single remaining kidney. Obstruction with hydronephrosis or pyonephrosis was present in I 2 cases and calculous disease was the cause of obstruction in eight of these. In the remaining three cases, obstruction was the result of ureteral stricture, presumed to be caused by chronic infection, inflammation and/or instrumentation. The obstruction was bilateral in eight and unilateral in four and in three of the four cases with unilateral obstruction, the contralateral kidney had been previously removed. Other findings included moderate to severe nephrosclerosis in six out of $2 \mathrm{I}$, renal adenomata in four out of $2 \mathrm{I}$ and papillary necrosis in three of the $2 \mathrm{I}$ patients. Polycystic kidney disease was present in one case and a renal cell carcinoma was found in one case.

Based on both clinical and pathological data, chronic pyelonephritis was judged to be a major factor in causing renal insufficiency in all $2 \mathrm{I}$ patients. Amyloidosis was also felt to be a major contributing factor to renal failure in 17 of these patients. Obstruction with pyonephrosis or hydronephrosis was felt to directly contribute to renal insufficiency in I I patients and in eight of these, calculous disease was the cause of obstruction. Acute pyelonephritis, renal and perinephric abscess formation, papillary necrosis and nephrosclerosis were present in six, five, three and six patients, respectively, and may have further contributed to renal insufficiency in these cases.

The major cause of death in the SCI-ESRD patients (Table II) was sepsis, documented by positive blood cultures in 13 cases ( 12 cases were gram negative, one case was gram positive). Furthermore, in three additional cases, where the cause of death was unknown, gram negative sepsis was strongly suspected clinically. The second most common cause of death in this group was cardiac tamponade (two cases). Evidence for

TABLE II

Primary cause of death in 2 I SCI-ESRD patients and 43 ambulatory-ESRD patients

\begin{tabular}{|c|c|c|c|c|}
\hline Cause of Death & SCI-ESRD & Total & Ambulatory-ESRD & $\%$ Total \\
\hline Sepsis & I3 & $6 I \cdot 9$ & 5 & I I 6 \\
\hline Gram Negative & 12 & & 3 & \\
\hline Gram Positive & I & & 2 & \\
\hline Bronchopneumonia & I & $4 \cdot 8$ & 7 & $16 \cdot 3$ \\
\hline \multicolumn{5}{|l|}{ Acute Myocardial } \\
\hline Infarction & I & $4 \cdot 8$ & I 4 & $32 \cdot 5$ \\
\hline Cardiomyopathy & - & - & 7 & $16 \cdot 2$ \\
\hline Cardiac Tamponade & 2 & $9 \cdot 5$ & 2 & $4 \cdot 7$ \\
\hline Hyperkalemia & 一 & - & 3 & $7 \cdot 0$ \\
\hline Malignancy & I & $4 \cdot 8$ & 2 & $4 \cdot 7$ \\
\hline Hepatic Encephalopathy & - & - & I & $2 \cdot 3$ \\
\hline Unknown & $3^{\star}$ & $14 \cdot 2$ & 2 & $4 \cdot 7$ \\
\hline
\end{tabular}

$\star$ Sepsis was clinically suspected 
acute pericarditis was present in seven patients while eight additional patients had evidence for chronic pericarditis. In contrast to the ambulatory -ESRD patients, acute myocardial infarction was the cause of death in only one case. Acute bronchopneumonia and metastatic adenocarcinoma of the gall bladder were the cause of death in one case each.

\section{Ambulatory-ESRD patients}

Renal pathological findings and major causes of renal failure are listed in Table III. Eighty-four kidneys from 43 subjects were examined; in two patients prior unilateral nephrectomies had been performed for chronic infection and obstruction and suspected hypernephroma, respectively. The most common pathological finding was chronic interstitial nephritis (CIN) present in 39 of the 43 patients. The interstitial changes were graded as mild to moderate in 32 patients and severe in only seven patients. Furthermore, based on both clinical and pathological findings, a diagnosis of chronic pyelonephritis could be made in only 12 of these patients. Nephrosclerosis was the next most common finding, present in 28 of the 43 . These changes were graded as mild-to-moderate in $2 \mathrm{I}$ patients and severe in seven patients. All the patients with nephrosclerosis were noted to be clinically hyperten-

TABLE III

Major cause of death

\begin{tabular}{|c|c|c|c|c|c|c|}
\hline $\begin{array}{l}\text { Pathological findings or } \\
\text { diagnosis }\end{array}$ & $\begin{array}{l}\text { No. of } \\
\text { cases } \\
\text { present }\end{array}$ & $\begin{array}{c}0 / 1 \\
\text { Total }\end{array}$ & $\begin{array}{l}\text { Major } \\
\text { cause of } \\
\text { renal } \\
\text { failure }\end{array}$ & Total & $\begin{array}{l}\text { May } \\
\text { have } \\
\text { contri- } \\
\text { buted to } \\
\text { renal } \\
\text { failure }\end{array}$ & $\begin{array}{c}\% \\
\text { Total }\end{array}$ \\
\hline
\end{tabular}

Chronic Pyelonephritis

Acute Pyelonephritis

$\star \mathrm{CIN}$

†CGN

Lupus Nephritis

Amyloidosis

Diabetic Glomerulosclerosis

Nephrosclerosis

PCKD

Calculous Disease

Obstructive Uropathy

Renal Artery Occlusion

Cholesterol Emboli

Vasculitis

Scleroderma

Papillary Necrosis

Renal Cell Carcinoma

Adenoma

Acquired Cystic Disease

\begin{tabular}{rccccc} 
I2 & $27 \cdot 9$ & 2 & $4 \cdot 7$ & IO & $23 \cdot 3$ \\
I & $2 \cdot 3$ & - & - & - & - \\
27 & $62 \cdot 8$ & 5 & I I.6 & 22 & 5 I.2 \\
6 & 14 & 6 & I4 & - & - \\
2 & $4 \cdot 7$ & 2 & $4 \cdot 7$ & - & - \\
2 & $4 \cdot 7$ & 2 & $4 \cdot 7$ & - & - \\
6 & 14 & 6 & 14 & - & - \\
28 & $65 \cdot 1$ & 7 & I6.3 & 2 I & $48 \cdot 8$ \\
6 & 14 & 6 & 14 & - & - \\
I & $2 \cdot 3$ & - & - & I & $2 \cdot 3$ \\
2 & $4 \cdot 7$ & I & $2 \cdot 3$ & I & $2 \cdot 3$ \\
I & $2 \cdot 3$ & I & $2 \cdot 3$ & - & - \\
3 & 7 & 2 & $4 \cdot 7$ & I & $2 \cdot 3$ \\
I & $2 \cdot 3$ & I & $2 \cdot 3$ & - & - \\
2 & $4 \cdot 7$ & 2 & $4 \cdot 7$ & - & - \\
I & $2 \cdot 3$ & - & - & I & $2 \cdot 3$ \\
I & $2 \cdot 3$ & - & - & - & - \\
4 & $9 \cdot 3$ & - & - & - & - \\
I2 & $27 \cdot 9$ & - & - & - & - \\
\hline
\end{tabular}

$\star$ Chronic Interstitial Nephritis of unknown etiology

†Nonspecific Chronic Glomerulonephritis 
sive. There were Io additional patients with hypertension, in whom no nephrosclerotic changes were noted. Three patients with moderate to severe nephrosclerosis were also noted to have multiple cholesterol emboli, in two cases the emboli were extensive and were reported to be the major cause of renal insufficiency.

Major glomerular pathology was present in I6 of the 43 cases. Six patients who were known diabetics had extensive diffuse and nodular intercapillary glomerulosclerosis. Six additional cases were diagnosed as nonspecific chronic glomerulonephritis and all carried a clinical diagnosis of idiopathic chronic glomerulonephritis. Two cases were known to have long standing SLE with diffuse proliferative nephritis diagnosed by renal biopsy. The post mortem renal pathology was described as showing both membranous and proliferative disease and fibroepithelial crescents were present in one patient. Two cases of renal amyloidosis with extensive glomerular involvement were also noted; one patient was known to have primary amyloidosis, the remaining case was diagnosed as having amyloidosis secondary to chronic inflammatory bowel disease.

Polycystic kidney disease (PCKD) was found in six of the 43 and was the primary cause of renal failure in these cases. Two cases of systemic sclerosis and one case of polyarteritis nodosa (PAN) were diagnosed and the renal pathology showed extensive evidence for these diseases in the respective patients. Acute pyelonephritis, calculous disease, obstructive uropathy and papillary necrosis were uncommon findings and were not major contributors to renal insufficiency in the group as a whole. A renal cell carcinoma was incidentally found in one patient, multiple small renal adenomas were present in four cases and acquired cystic disease was diagnosed in 12 patients.

The major cause of death in this group (Table III) was acute myocardial infarction (I 4 of the 43 cases), followed by cardiomyopathy with refractory congestive heart failure and pulmonary (oedema) oedema ( 7 of the 43 cases), acute bronchopneumonia ( 7 of the 43 cases), sepsis (5 of the 43 cases), hyperkalaemia ( 3 of the 43 cases), cardiac tamponade ( 2 of the 43 cases), metastatic carcinoma ( 2 of the 43 cases) and end-stage liver disease with hepatic encephalopathy ( $\mathrm{I}$ of the 43 cases). In two patients with scleroderma, the primary cause of death could not be determined.

\section{Discussion}

In the SCI-ESRD patients, the most consistent and dominant process involving the kidneys was chronic pyelonephritis, present in all cases. Furthermore, the extent of disease was noted to be severe in all cases and no doubt was the major contributor to renal failure in these patients. These findings are quite similar to those reported by Tribe and Silver on paraplegic patients in the predialysis era, where pyelonephritis was found to contribute to renal failure in 95 per cent of cases studied. (Tribe and Silver, I969).

The second most common pathological process involving the kidneys was amyloidosis, present in 8I per cent of cases. The extent of disease was judged to be moderate to severe in all cases and was also a major contributor to renal insufficiency in these patients. It is well established that the amyloidosis associated with paraplegia is the result of chronic suppuration related to urinary tract infection, pressure sores and chronic 
osteomyelitis that often complicate spinal cord injury. (Tribe and Silver, I969). The incidence of renal amyloidosis of 8I per cent in our series is considerably higher than reported in other post-mortem studies on paraplegics. (Tribe and Silver, I969, Dalton et al., I965; Dietrick et al., I958). The most apparent explanation for this is that the duration of SCI was considerably longer in our patients, averaging 2 I years as compared, for example, to an average survival time following paraplegia of only io years, reported by Tribe and Silver (Tribe and Silver, I969). The reasons for this increased survival are not entirely clear and are only partly explained by the availability and use of supportive haemodialysis as the mean duration of dialysis in our patients was only I 6.5 months. Other responsible factors were probably related to more effective treatment of life threatening infections and related complications.

Clinical and pathological evidence for serious acute bacterial infections involving the kidneys and urinary tract were also commonly present in the SCI-ESRD group. Acute pyelonephritis, perinephric abscess formation and/or obstruction with pyonephrosis were evident in six, five and nine cases, respectively. Furthermore, bacterial sepsis was determined to be the primary cause of death in 16 patients and the urinary tract was the likely source for sepsis in I I of these.

Another common finding in the SCI patients was renal calculous disease, present in 48 per cent of cases at postmortem. The calculi tended to be multiple, involving the pelvi-calyceal system and proximal ureter and were associated with obstruction and hydronephrosis or pyonephrosis in eight patients. Although chemical analysis was not performed, a recent study by our group on surgically removed stones from paraplegic patients showed 25 of 26 calculi to be composed of 90 per cent magnesium ammonium phosphate and Io per cent calcium apatite (Nikakhtar et al., I98 I). Urinary tract infection with urea splitting organisms was determined to be the most important factor in the pathogenesis of urolithiasis in these patients, however, other factors including immobilization hypercalciuria, hyperoxaluria, reduced urinary citrate and urinary stasis may also contribute to this problem (Burr, I972; Freeman 1949; Vaziri et al., I 982).

It is generally agreed that urinary obstruction is the primary underlying condition predisposing to urinary tract infection in SCI (Guttman, I976; Tribe and Silver, I 969). Virtually all of these patients have some degree of obstruction due to neuropathic bladder dysfunction and/or hydrodynamic dysfunction of the ureter or urethra. Other major causes of obstruction in SCI include renal calculi, catheter plugging or malfunction and ureteric fibrosis with stricture formation related to instrumentation and/or chronic infection. In the present series 12 cases of marked obstruction were noted, nine cases of pyonephrosis and three cases of hydronephrosis. As previously indicated, calculous disease was the cause of obstruction in eight of these cases, and was a major factor associated with pyonephrosis in our patients. Furthermore, renal or perinephric abscess formation was found to complicate pyonephrosis in five cases. Based on this information plus the fact that the abscesses were either intrarenal medullary (one case) or perinephric (four cases), we concluded that abscess formation was the direct result of calculous disease, obstruction and pyonephrosis rather than the result of haematogenous spread of bacteria from a distant site.

Interestingly, clinical hypertension and nephrosclerosis were noted in 
only 33 per cent and 29 per cent of the SCI patients, respectively. In comparison 65 per cent of the ambulatory patients had nephrosclerotic changes and 88 per cent were recognized to be hypertensive antemortem. In addition, an 80 to 90 per cent prevalence of hypertension, overall, has been described in ESRD (Lazarus and Kjellstrand, I98I). Although the reasons for this apparent reduced frequency of hypertension and nephrosclerosis in the SCI-ESRD patients are not known, several possibilities may be considered. First of all, causes of ESRD such as CGN, diabetes mellitus and PCKD that are often complicated by moderate to severe hypertension appear to be less common in SCI-ESRD patients. Second, as the major aetiology of renal failure in SCI is related to chronic infection and obstruction with tubular interstitial damage, salt wasting and polyuria could result in amelioration of the volume component of hypertension associated with ESRD. Third, the hypoalbumin-aemia commonly present in SCI-ESRD patients, due primarily to increased protein losses through the skin and urinary tract, would result in reduced intravascular oncotic pressure that could also lead to a reduction in intravascular volume and pressure.

Evidence for papillary necrosis was present in I4 per cent of the SCI patients. In previous autopsy studies involving SCI patients, papillary necrosis has not been a commonly described finding (Konwaler, I 953; Tribe, I963). Tribe and Silver, however, reported six cases of necrotising papillitis in 70 paraplegics studied postmortem, (Tribe and Silver, I969). It appears that chronic obstruction and infection that frequently complicate SCI predispose these patients to this condition. Also, it appears safe to assume that papillary necrosis may play a significant role in contributing to the development of ESRD in some patients with SCI, although the actual magnitude of this problem remains to be determined.

The presence of renal adenomas has been previously reported in several autopsy studies (Childs and Waterfall, I953; Fuchsman and Angrist, I948). Tribe and Silver found small renal adenomas in 2 I per cent of IO4 kidneys examined histologically (Tribe and Silver, I969). They further noted that adenomas tended to occur in paraplegics who died from renal failure and had evidence of chronic pyelonephritis. Other authors, however, have described an association between renal adenomas and nephrosclerosis. (Childs and Waterfall, I953). In our SCI patients, multiple, small papillary adenomas were present in 4 cases ( 19 per cent) that ranged in size from 3 to $8 \mathrm{~mm}$ in diameter. All four cases had chronic pyelonephritis while coexisting nephrosclerosis was present in only one of these patients. Interestingly, in the ambulatory-ESRD group, small adenomata were also noted in four patients ( 9 per cent) and coexisting nephrosclerosis was present as the dominant renal lesion in all four while evidence for chronic pyelonephritis was present in only one of these patients. It should, however, be taken into consideration that chronic pyelonephritis was present in all of our SCI patients while nephrosclerosis was present in only 29 per cent. Conversely, in the ambulatory ESRD group, nephrosclerosis was present in 65 per cent while only 5 per cent had chronic pyelonephritis. It is difficult, therefore for us to draw any conclusions regarding an association between chronic pyelonephritis or nephrosclerosis and renal adenomata.

The incidence of acquired renal cystic disease (ACD) among the SCI 
patients was considerably less than that found in the ambulatory group. The reason for the observed difference is not entirely clear, however, shorter survival on maintenance dialysis in SCI group may have been responsible. This is consistent with recent investigations in ambulatory dialysis patients where the incidence of ACD positively correlated with the duration of dialysis treatment. (Lazarus et al., I975; Linder et al., I 974).

In the ambulatory-ESRD group, both the clinical and histopathological findings were markedly different. Acute and chronic glomerular diseases, PCKD, hypertensive nephrosclerosis and apparent chronic interstitial nephritis of unknown etiology were the major causes of renal insufficiency. Furthermore, the ambulatory patients had much less evidence for acute and chronic pyelonephritis, calculous disease, obstruction and abscess formation. That evidence for necrotising papillitis and papillary necrosis was present in only one case may further reflect the lower incidence of obstruction and infection in this group. Secondary amyloidosis was also much less prevalent in accordance with the lower incidence of chronic infection and suppuration.

As previously indicated, sepsis was the leading cause of mortality in the SCI patients accounting for 76 per cent of deaths (Table 3). Sepsis was predominantly gram negative with the main identifiable sources being the urinary tract and decubitus ulcer infections. In a number of cases cross contamination between the urinary tract and infected decubiti occurred creating a dual source for disseminated infection. Cardiovascular disease, although the second leading cause for mortality in this group, was the direct cause of death in only three cases. In contrast, cardiovascular disease was the leading cause of mortality in ambulatory patients with acute myocardial infarction, cardiomyopathy and cardiac tamponade accounting for 33 per cent, I 6 per cent and 5 per cent of deaths, respectively. In ESRD, an increased cardiovascular mortality rate has been well documented being ascribed to a number of factors including hypertriglyceridemia, hypertension, pericarditis and secondary hyperparathyroidism that are commonly present in this setting. (Dunnill et al., I977; Mirahmadi and Vaziri, I980). Although infection was the second leading cause of death in ambulatory patients with pneumonia and sepsis accounting for $\mathrm{I} 6$ per cent and 12 per cent of deaths respectively, the magnitude of this problem was considerably less than in the SCI patients. The mortality figures in our ambulatory patients are in general agreement with other currently published data on maintenance hemodialysis patients with cardiovascular disease and infection being the major causes of death.

\section{Summary}

The SCI-ESRD patients exhibited markedly different clinical and renal histopathological data when compared to the ambulatory ESRD patients. Chronic pyelonephritis and amyloidosis dominated the findings and were the major causes of renal insufficiency. Acute pyelonephritis, papillary necrosis, calculous disease, pyonephrosis and perinephric abscess formation were also more frequently present in these patients. These data are in general agreement with previous post-mortem studies on paraplegia and again supports the observation that neuropathic bladder dysfunction is the basic underlying condition predisposing to renal injury by setting the stage for urinary tract infection and subsequent development of renal parenchymal 
infection, calculous disease, obstructive uropathy and/or amyloidosis. Hypertension and nephrosclerosis, which were common findings in the ambulatory patients were comparatively rare in the SCI patients. Although the reasons for this were not clear, we have speculated that hypoalbuminaemia, and possible increased renal sodium or water excretion may have been responsible. Furthermore, it was apparent from our data that conditions associated with both renal insufficiency and moderate to severe hypertension were relatively uncommon in the SCI setting. The incidence of ACD was also considerably less in the SCI-ESRD patients. This finding is thought to be related to the shorter survival of SCI patients on maintenance dialysis.

With the current wide spread application of supportive dialysis, uraemia per se is no longer a significant cause of mortality in SCI. Gram negative sepsis was the predominant cause of death in our SCI-ESRD patients, while death secondary to cardiovascular disease predominated in the ambulatory-ESRD group. In addition, the urinary tract and decubitus ulcers were determined to be the major source for sepsis in the SCI patients. More effective prevention or control of these infections no doubt would result in not only a lower incidence of renal failure in these patients, but also substantially reduced morbidity and mortality.

\section{RÉSUMÉ}

Dans l'étude actuelle nous exposons les constatations pathologiques rénales provenant de matériel d'autopsie ainsi que les données cliniques pertinents sur 2 I malades qui avaient subi des blessures de la moelle épinière et qui souffraient d'une maladie du rein dans sa période terminale (SCI-ESRD) qu'on avait traités par l'hémodialyse de maintien. On compare ces données avec les constatations cliniques et d'autopsie pertinentes sur 43 malades en dialyse décédés pendant la même periode.

Les malades SCI-ESRD montraient des données cliniques et histopathologiques rénales qui différaient nettement en comparaison avec le groupe ESRD ambulatoire. La pyélonéphrose et l'amylose chroniques dominaient les constatations et c'étaient les causes majeures d'insuffisance rénale. La pyélonéphrose aiguë, la nécrose papillaire, la maladie calculeuse, la pyonéphrose et la formation d'abcès perinéphriques étaient également plus fréquemment présentes chez les malades SCI-ESRD. L'hypertension et la néphrosclérose, qu'on a souvent constatées chez les malades ESRD ambulatoires étaient comparativement rares chez les malades SCI-ESRD. En plus, l'incidence de la maladie cystique acquise (ACD) était considérablement moindre chez le groupe SCI-ESRD. Bien que les raisons de ces constatations ne soient pas entièrement évidentes plusieurs explications possibles sont données.

L'infection avec la septicémie gram-négative était la cause prédominante de la mort chez les malades SCI-ESRD, tandis que la mort suivant la maladie cardiovasculaire prédominait chez le groupe ESRD ambulatoire. En outre, on a déterminé les voies urinaires et les escarres infectées comme la source principale de la septicémie chez les malades SCI. De ces constatations il s'ensuit qu'une prévention et un contrôle plus efficaces de ces infections résulteraient non seulement dans un moindre incidence d'un défaut du rein mais aussi dans une morbidité et une mortalité substantiellement réduites chez les SCI chroniques.

\section{ZUSAMMENFASSUNG}

Im jetzigen Papier berichten wir die nierenpathologischen Befunde aus Autopsiematerial zusammen mit betreffenden klinischen Angaben von 2 I Rückenmarkverletzungspazienten mit Endzustand-Nierenkrankheit (SCI-ESRD), die mit Erhaltungsblutentschlackung behandelt worden sind. Diese Angaben werden mit den betreffenden klinischen und Leichenöffnungsbefunden über 43 herumziehende Blutentschlackungspazienten, die während derselben Zeitperiode gestorben sind, verglichen.

Die SCI-ESRD-Pazienten zeigten bemerkenswert verschiedene klinische und nierenhistopathologische Angaben im Vergleich mit der herumziehenden ESRD-Gruppe. 
Chronische Pyelonephrose und Amyloidose beherrschten unter den Befunden, und diese waren die Hauptursachen der Nierenschwäche. Akute Pyelonephrose, Papillennekrose, Nierenstein-Krankheit, Pyonephrose und Nierenkapselabszessbildung befanden sich auch häufiger bei den SCI-ESRD-Pazienten. Hypertonie und Nierensklerose, die ganz übliche Befunde bei den herumziehenden ESRD-Pazienten waren, waren verhältnismässig seltsam bei den SCI-ESRD-Pazienten. Weiter war die Häufigkeit der erworbenen Zystenkrankheit (ACD) beträchtlich weniger bei der SCI-ESRD-Gruppe. Obwohl die Ursachen von diesen Befunden nicht vollkommen klar sind, werden verschiedene mögliche Erklärungen davon gegeben.

Ansteckung mit gramnegativer Sepsis war die beherrschende Todesursache bei den SCI-ESRD-Pazienten, während der aus Herzgefässkrankheit folgende Tod beherrschte bei der herumziehenden ESRD-Gruppe. Weiter sind die Harnwege und angesteckte Dekubitalgeschwüre schon als Hauptquelle der Sepsis bei den SCI-Pazienten festgestellt worden. Aus diesen Befunden ergibt sich, dass wirksamere Vorbeugung und Bekämpfung von diesen Ansteckungen nicht nur eine verringerte Häufigkeit des Nierenversagens, sondern auch eine wesentlich verringerte Anfälligkeit und Sterblichkeit bei den chronischen SCIPazienten zur Folge haben würden.

\section{REFERENCES}

BURR, R. G. (1972). Urinary calcium, magnesium, crystals and stones in paraplegia. Paraplegia, I0, 56-63.

Childs, P., WATERfall, W. B. (1953). Renal Adenoma: Review with report of two further cases. Brit f. Urol, 25, I87-194.

Dalton, J. J., Hackler, R. H. \& Bunts, R. C. (1965). Amyloidosis in the paraplegic; incidence and significance. F. Urol., 93, 553-555.

Dietrick, R. B. \& RUSSI, S. (I958). Tabulation and review of autopsy findings in fiftyfive paraplegics. F. Amer Med Assoc., 166, 4 I-44.

Dunnill M. S., Millard, P. R. \& Ogiver, D. (I977). Acquired cystic disease of the kidneys: A hazard of long-term intermittent maintenance hemodialysis. F. Clin Path., 30, 868877.

FREEMAN, L. W. (1949). The metabolism of calcium in patients with spinal cord injuries. Ann Surg., I29, I77-1 84 .

Fuchsman, J. J. \& Angrist, A. (I948). Benign renal tumors. F. Urol., 59, I67-i 73.

GutTMAN, L. (I976). Disturbances of the bladder and upper urinary tract. In: Sir Ludwig Guttman (ed): Spinal cord injuries, pp. 33I-457. London. Blackwell Scientific Publications.

Konwaler, B. E. (1953). Proceedings of the and Annual Clinical Spinal Cord Injury Conference. p. 42. Amer Veterans Adm.

Lazarus, J. M. \& KJEllstrand (I98I). Dialysis: Medical aspects. In: Brenner B. M., Rector R. C., Jr. (eds). The Kidney, p. 2490-2543. Philadelphia. W. B. Saunders Company.

Lazarus, J. M., Lowrie, E. G., Hampers, C. L. \& Merrill, J. P. (1975). Cardiovascular disease in uremic patients on hemodialysis. Kidney Int., 2 (suppl), I67-175.

Linder, A., Charra, B., Sherrard, D. J. \& Scribner, B. H. (I974). Accellrated atherosclerosis and prolonged maintenance hemodialysis. N. Engl. F. Med., 290, 697$70 \mathrm{I}$.

Mirahmadi, M. K. \& VAZIRI, N. D. (I980). Cystic transformation of end-stage kidneys in patients undergoing hemodialysis. Int. F. Artif. Organs, 3 (5), 267-269.

Mirahmadi, M. K., Vaziri, N. D., Ghobadi, M., Nikakhtar, B. \& Gordon, S. (I982). Survival on maintenance dialysis in patients with chronic renal failure associated with paraplegia and quadraplegia. Paraplegia, 20, 43-47.

Nikakhtar, B., Vaziri, N. D., Khonsari, F., Gordon, S. \& Mirahmadi, M. K. (I98I). Urolithiasis in patients with spinal cord injury. Paraplegia, 19, 363-366.

Pearce, L. S., Perkins, H. E. \& Holladay, L. W. (I964). Spinal Cord Injury: Statistical review of 35 autopsy cases. Proceeding of the Annual Clinical Cord Injury Conference, 13, 88-93.

Tribe C. R. \& Silver J. R. (1969). 'Renal Failure' in Paraplegia, pp. 3-107, London, Pitman.

Tribe, C. R. (1963). Causes of death in the early and late stages of paraplegia. Paraplegia, I, I $9-47$.

Vaziri, N. D., NikakhtaR, B. \& Gordon, S. (1982). Hyperoxaluria in chronic renal disease associated with spinal cord injury. Paraplegia, 20, 48-53. 